\title{
The Distribution of Human Intestinal (Stool) Parasites with Respect to Gender and Age in a District Hospital Setting in Biyem-Assi Yaoundé: A Retrospective Study
}

\author{
Ekwale Emilia Ada \\ PhD Research Student, Faculty of Education, University Of Buea, Cameroon
}

\begin{abstract}
In this study, the distribution of human stool parasites with respect to gender and age was reviewed in a retrospective and descriptive study. Patient's records over two years (1995 and 1996) were reviewed at the Biyem - Assi District Hospital in Yaoundé. During the study period, 1387 patients suspected to have been suffering from intestinal parasites according to their symptoms had their stools analyzed in the laboratory of this hospital.
\end{abstract}

The objectives of the study were:

1. To investigate whether the global prevalence of intestinal parasites is below $50 \%$

2. To investigate whether the positive cases of intestinal parasites are lower than the negative cases.

3. To investigate whether mates haves higher risk of intestinal parasites than females.

4. To investigate whether the prevalence rate of intestinal parasites is higher in adolescents especially between the ages of 11 -15 years.

5. To investigate whether the most prevalent intestinal protozoa is Entamoeba histolytica and whether the most prevalent intestinal helminthe is Ascaris lumbricoides.

6. To investigate whether the prevalence rate of Entamoeba histolytica is higher in males than in females and whether the prevalence rate of Ascaris lumbricoides is higher in females than in males.

7. To investigate whether the most prevalent intestinal protozoa which occurs between the ages 0 - 15 years is Entamoeba histolytica while the most prevalent intestinal helminthes between the ages of $0-15$ years are Trichiuris trichiura and Ascaris lumbricoides.

8. To investigate whether there is the existence of associations between human intestinal helminthes; between human intestinal protozoa and between human intestinal helminthes and protozoa.

The hypotheses stated in the null form were: Development

1. The global prevalence of intestinal parasites is not below $50 \%$.

2. The positives cases of intestinal parasites are not lower than the negative cases.

3. The males do not have a higher risk of intestinal parasites than females.

4. The prevalence of human intestinal parasites is not high in adolescents between the ages of $11-15$ years.

5. The most prevalent intestinal protozoa is not Entamoeba histolytica while the most prevalent intestinal helminthe is not Ascaris lumbricoides.

6. The prevalence rate of Entamoeba histolytica is lower in males than in females and the prevalence rate of Ascaris lumbricoides is lower in females than in males.

7. The most prevalent intestinal protozoa which occurs between the ages of $0-15$ years is not Entamoeba histolytica while the most prevalent intestinal helminthes between the ages of $0-15$ years are not Trichiuris trichiura and Ascaris lumbricoides.

8. There are no associations between human intestinal helminthes/human intestinal helminthes; between human intestinal protozoa/human intestinal protozoa and between human intestinal helminthes /human intestinal protozoa

KEYWORDS: Distribution, Human intestinal parasites, Gender, Age, District hospital setting, Retrospective study, Entamoeba histolytica, Entamoeba coli, Trichomonas intestinalis, Giardia intestinalis, Ascaris lumbricoides, Trichuris trichiura, Ankylostoma duodenale, Hymenolepis nana, Ascaridiosis

\section{INTRODUCTION}

The World Health Organization (WHO) lays emphasis more on the preventive than the curative approach to diseases. Any preventive method must be based on the epidemiology of the disease.

"A parasite is an organism living in or on another living organism and deriving its nutriment partly or wholly from it, usually exhibiting some special adaptation and often causing death or damage to its hosts" (New Webster's Dictionary 1993)
Intestinal (stool) parasites designate an assembly of organisms that include protozoas such as Entamoeba histolytica, round worms such as Ascaris lumbricoides and flatworms (Cestodes) such as Taenia solium and Taenia saginata which pass part or the totality of their existence in the digestive tract. These parasites affect an average of one person out of three in the world and one Cameroonian out of two, (Ekobo 1997). The proliferation of these parasites in linked to measures of elementary hygiene which comprise 
water hygiene, food hygiene and faeco-urinary hygiene (proper disposal of faeces and urine).

These intestinal parasites cause a lot of harm. For example Entamoeba histolytica causes amoebic dysentery and liver abscesses. Taenia solium and Taenia saginata (pork and beef tape worms respectively) cause anaemia, as they use their hooks and suckers to anchore in the small intestines; epilepsy by Taenia solium especially when the larvae are found in the brain; psychiatric disturbances and mental deterioration (Cysticercosis); Ascaris lumbricoides cause ascaridiosis with clinical manifestations such as anaemia, abdominal discomfort, distension and obstructions if the worms occur in large numbers and intestinal perforations; hook worms such as Ankylostoma duodenale and Necator americanus cause inflammation of the lungs/coughing, fever etc. When the larvae migrate through the lungs, they can also cause anaemia and diarrhea accompanied by blood stained stool, stunted growth and mental retardation. Fishbein's encyclopaedia (1987); Trichuris trichiura causes trichuriasis with clinical manifestations such as bloody diarrhea, anaemia and prolapsed of the rectum especially in malnourished children; Enterobius vermicularis (pin worm) causes enterobiasis with clinical manifestations such as itching of the anus, general irritability, difficulties in sleeping and short attention span in school, appendicitis, ulcers and perforations of intestinal wall; Trichinella spiralis causes trichinosis whose clinical manifestations are fever, muscle ache and eye swellings. In severe infections, the heart and breathing muscle are weakened to the point of death. Strongyloides stercoralis causes strongyloidiasis with clinical manifestations such as gastro-intestinal upsets and discomfort in heavy infections, serious skin lesions, oedema and itching of the finger-tips.

From the above analysis of the symptoms caused by the intestinal parasites, their harm to humans cannot be underestimated. These parasites affect both the males and females at various ages and are unequally distributed as per gender and age. From the work of Ekobo (1997) on the distribution of intestinal parasites with respect to age, it was found out that, ascaridiosis affects children mostly, that is children are the risk group.

Most of the stool parasites can be identified with the use of the microscope. The protozoans such as Entamoeba histolytica can be observed under the microscope in a small quantity of $0.9 \%$ salt solution. The cysts can be identified under the microscope when they are stained with iodine (lugol). The worms and their eggs can be identified under the microscope directly that is without staining; (Black-lock and Southwell 1977). The identification of Enterobius vermicularis (pin worm) can be done by applying a sticky piece of transparent cellophane tape on the end of a glassrod over the anal area and the tape is removed and moistened and viewed under the microscope for the eggs and adult worms, (Pascoe et al 1979).

The intestinal parasites can be prevented by drinking clean water, by eating properly cooked food especially meat, by proper disposal of faeces and by preventing the walking about by children with bare legs. Finger nails should be cut.

The intestinal parasites can be treated by chemotherapeutic agents. Amoebic dysentery is treated with Metronidazole (Flagyl), (Pascoe et al 1979). Cysticercosis can be treated with Mepacrine which causes expulsion of the whole worm instead of Dichlorophen or Nicolsamide which digest the segments and may liberate the eggs which may become infective to other persons. Ascariasis or ascaridiosis can be treated with Piperazine salts (citrate, adipate or phosphate); (Maegraith 1971). Hook worms can be treated with Bephenium hydroxynaphthoate (Alcopar); Maegraith 1971); trichuriasis can be treated with Mebendazole, (Jawetz et al 1980). Enterobiasis can be treated with drugs like Poram, Vermox or Anterpar. Trichinosis is treated with the drug Thiabendazole and corticosteroids help to relieve the muscle symptoms and fever; (Jawetz et al 1980). Strongyloidiasis can be treated with Thiabendazole; (Maegraith 1971).

The effects caused by intestinal parasites cannot be underestimated in Africa as a whole and Cameroon in particular. Intestinal parasites cause infant mortality, reduced economic production and reduced academic potentialities due to mental retardation.

\section{BACKGROUND}

Hoge, Shlim \& Rajah (1993) carried out a study on epidemiology of diarrhea illness associated with coccidianlike organisms among travelers and foreign residents in Nepal and found out that, the prevalence was $11 \%$.

Intestinal parasites have attracted the attention of some authors in Cameroun. In a recent study, the distribution of parasites both protozoans and helminthes in the different regions of Cameroun and different localities of Yaoundé has been established (Ekobo, 1997). These parasites have been found to affect $51.24 \%$ of the male population and $55.93 \%$ of the female population. The female sex therefore had a higher risk of being affected. Five species of nematodes and one species of protozoan were identified in Cameroon, which are Ascaris lumbricoides, Trichuris, trichiura, Necator americanus, Enterobius vermicularis, and Strongyloides stercoralis for the nematodes and Entamoeba histolytica for the protozoan. In this very study, children have been found to have higher rates of intestinal parasitic infestation.

\section{PROBLEM STATEMENT}

Intestinal parasites cause many health hazards and even death. Their effects cannot be over looked as they cause anatomical and physiological damages of human cells, tissues and organs.

During their parasitic life, the helminthes and the protozoa secrete in the course of their metabolism substances which contain toxins. These toxins react in a selective way on the nervous system and on the general state of the parasitized subjects generating all sorts of toxic effects, (Ekobo, 1997).

From the above analysis, it can be seen that intestinal parasites cause an array of health problems to humans and thus needs medical attention in order that preventive and curative measures of low cost should be implemented.

The justification of this research work is that in the scientific world in general and the medical field in particular, the aim is to reduce cost as far as possible, therefore it is routine in most health facilities to perform a stool analysis of various parasites and identification and treatment modalities practiced. If one knows the common parasites which frequently attack a certain gender and age group, and the specific drugs known, it will be cost effective to prescribe 
specific treatment without having to pay for stool analysis which is often costly. In so doing, the cost for medical care will reduce and this will go a long way to help people especially in developing countries like ours with low per capita income.

\section{THEORIES}

Ekobo, (1997), theorized that, the prevalence of intestinal parasites is generally above $50 \%$.

Hoge, Shlim \& Rajah (1993); Ekobo, (1997); Ning Tang \& Nian Ji Luo (2003); Ashok, Suguneswari, Satish and Kesavaran (2013); Ram Bilkshan Sah, Sailesh Bhattarai \& Paras Kumar Pokharel (2013) theorized that Ascaridiosis (Ascaris lumbricoides infection) affects children more than any age group.

Ekobo (1997) theorized that, human intestinal parasites affect an average of one person out of three in the world and one Cameroonian out of two.

Ekobo, (1997); Ning Tang \& Nian Ji Luo (2003); Ram Bilkshan Sah, Sailesh Bhattarai \& Paras Kumar Pokharel (2013) theorized that, $51.24 \%$, of the male population and $55.93 \%$ of the female population are affected by intestinal parasites that is the prevalence of intestinal parasites in the females is higher than in males.

Ekobo (1997), therorized that the most prevalent intestinal protozoan was Entamoeba histolytica and the most prevalent intestinal helminthe was Ascaris lumbricoides.

Ekobo (1997); Ning Tang \& Nian Ji Luo (2003) theorized that associations exist between intestinal parasites and that this would help in that, once a particular parasite is isolated, systematic treatment of its associates will be necessary.

\section{METHODOLOGY}

The study was carried out in the laboratory of the BiyemAssi district hospital. This rapidly growing health facility was until now a small centre that catered for minor ailments. It is among the sixteen health units chosen by the World Bank to be restructured and upgraded to a full hospital. The presence of specialist doctors in the hospital as by 1998 (two obstetricians, two gynaecologists, one dental surgeon and one pediatrician) immensely increased the patient turnover. The laboratory has therefore become one of the busiest state owned hospital based laboratories.

This research work was a retrospective, descriptive and analytic study in which past records for the last two years (1995 to 1996) were examined.

Past records in the Biyem-Assi hospital laboratory from 1995-1996 were cross-checked. Suspected intestinal parasite cases referred to this laboratory for stool analysis were used as a guide to sort out those who were positive for intestinal parasites. Patients' identifications such as gender, age group and nature of the laboratory results (either positive or negative) were noted.

The data for this research was collected by using standard questionnaires. Each questionnaire was used to extract the information about each patient in the past records of the laboratory. The information includes gender, age, and type of parasite present and whether the results were positive or negative.

The $\mathrm{x}^{2}$ (chi square) was used to verify if the differences between the following variables were statistically significant. Negative and positive cases of intestinal parasites; Positive results in the males as against the females; Entamoeba histolytica load in both males and females.

The formular of $X^{2}$ (chi square) used as statistical test was:

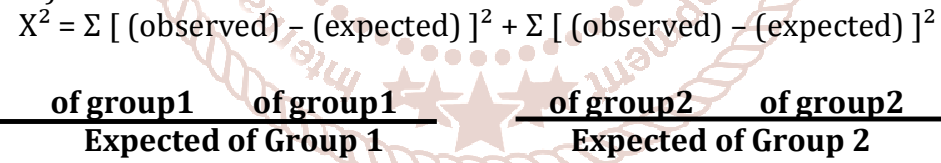

$\Sigma=$ sign of summation.

Excluded from our data collection were incomplete cases of laboratory stool analysis.

Since the study was retrospective, a standard questionnaire was used to fill in information from the laboratory past record book about the people who came to the laboratory for stool analysis. Laboratory materials were not needed in this study since it was dealing with past records of the BiyemAssi hospital laboratory.

\section{RESULTS}

The total number of patients who came to the Biyem-Assi hospital laboratory for stool examination during the study period, 1995 - 1996 was 1,387. These were patients suspected to have intestinal parasites as defined by their symptomatology. The total population was divided into males and females within the age groups of below 5 years, 5 - 10 years, $11-15$ years, $16-20$ years, $21-25$ years and 26 years and above. There were 490 positive cases giving a prevalence rate of $35.33 \%$.

\section{ANALYSIS OF HYPOTHESIS 1}

Table 1: Table of the global prevalence of the positive cases of intestinal parasites

\begin{tabular}{|c|c|c|}
\hline $\begin{array}{c}\text { Global prevalence } \\
\text { of positive cases of } \\
\text { intestinal parasites }\end{array}$ & \multicolumn{2}{|c|}{} \\
\hline $\begin{array}{c}\text { Total } \mathrm{N}^{\circ} \text { of positive } \\
\text { cases }\end{array}$ & $\begin{array}{c}\text { Total } \mathrm{N}^{\circ} \text { of } \\
\text { cases who } \\
\text { came for exams }\end{array}$ & $\begin{array}{c}\text { Prevalence } \\
\text { rate }\end{array}$ \\
\hline 490 & 1,387 & $35.33 \%$ \\
\hline
\end{tabular}

Up to $35.35 \%$ of patients who attended the Biyem-Assi district hospital with gastro-intestinal symptoms were positive for intestinal parasites.

Therefore, the hypothesis that the global prevalence of the intestinal parasites is below $50 \%$ in retained. 
International Journal of Trend in Scientific Research and Development (IJTSRD) @ www.ijtsrd.com eISSN: 2456-6470

ANALYSIS OF HYPOTHESIS 2

Table 2: Table of the number of cases positive and negative for intestinal parasites and their prevalence rates

\begin{tabular}{|c|c|c|c|}
\hline \multirow{2}{*}{} & \multicolumn{3}{|c|}{$\begin{array}{c}\text { Prevalence rates of intestinal parasites } \\
\text { both positive and negative cases }\end{array}$} \\
\cline { 2 - 4 } & Positive & Negative & Total \\
\hline $\mathrm{N}^{\circ}$ of cases of intestinal parasites & 490 & 897 & 1,387 \\
\hline Prevalence rates of intestinal parasites in $\%$ & $35.33 \%$ & $64.67 \%$ & $100 \%$ \\
\hline
\end{tabular}

Table 3: $\mathrm{X}^{2}$ distribution of the number of positive cases for intestinal parasites

\begin{tabular}{|c|c|c|c|}
\hline Groups & Positive & Negative & Total \\
\hline Observed & 490 & 897 & 1,387 \\
\hline Expected & 462.3 & 924.6 & $1,387.00$ \\
\hline $\mathrm{X}^{2}$ & 1.659 & 0.823 & 2.482 \\
\hline
\end{tabular}

Total proportion is $2+1=3$.

$\mathrm{X}^{2}=2.482$

$\mathrm{df}=2-1=1 \quad\} \alpha>0,10$

The calculated $\mathrm{X}^{2}$ value $=2.482$. The critical or table value of $\mathrm{X}^{2}$ at 0.05 level of significance was 0.455 . Since the calculated value of $X^{2}$ is greater than the critical value, it shows that the difference is statistically significant and thus the hypothesis that positive cases of intestinal parasites are lower than the negative cases is retained or validated.

From this retrospective study, 692 females and 695 males came to the laboratory for stool examination and out of these, 233 females were positive for intestinal parasites while 257 males were positive for intestinal parasites.

\section{ANALYSIS OF HYPOTHESIS 3}

Table 4: Prevalence rates of intestinal parasites in function of gender

\begin{tabular}{|c|c|c|c|}
\hline & \multicolumn{2}{|c|}{ Prevalence rates of intestinal parasites in function of Gender } \\
\hline Sex & Females & Males & Total \\
\hline $\mathrm{N}^{\circ}$ of positive cases & 233 & 257 & 490 \\
\hline Prevalence rates of positive cases in $\%$ & $47.55 \%$ & $52.45 \%$ & $100 \%$ \\
\hline
\end{tabular}

Table 5: $\mathrm{X}^{2}$ distribution of the positive cases of intestinal parasites in function of sex

Total proportion is $1+1=2$

$\mathrm{X}^{2}=1.174$

$\mathrm{df}=2-1=1\} \boldsymbol{\alpha}>0.20$

\begin{tabular}{|c|c|c|c|}
\hline Groups & Females & Males & Total \\
\hline Observed & 233 & 257 & 490 \\
\hline Expected & 245.0 & 245.0 & 490.0 \\
\hline$X^{2}$ & 0.587 & 0.587 & 1.174 \\
\hline
\end{tabular}

The calculated $\mathrm{X}^{2}$ value $=1.174$. The critical or table value of $\mathrm{X}^{2}$ at 0.05 level of significance was 0.455 . Since the calculated value of $X^{2}$ is greater than the critical value, it shows that the difference is statistically significant and thus the hypothesis that males have a higher risk for intestinal parasites than females is retained or validated. This contradicts Ekobo, (1997); Ning Tang \& Nian Ji Luo (2003); Ram Bilkshan Sah, Sailesh Bhattarai \& Paras Kumar Pokharel (2013) who theorized that, 51.24\%, of the male population and $55.93 \%$ of the female population is affected by intestinal parasite.

\section{ANALYSIS OF HYPOTHESIS 4}

Table 6: Prevalence rates of intestinal parasites in function of age

\begin{tabular}{|c|c|c|c|c|c|c|c|}
\hline & \multicolumn{4}{|c|}{ Prevalence rates of intestinal parasites in function of age } \\
\hline Age & 1 & 2 & 3 & 4 & 5 & 6 & Total \\
\hline Positive cases & 49 & 87 & 66 & 80 & 81 & 94 & 457 \\
\hline $\mathrm{N}^{\circ}$ of people examined under each age group & 157 & 142 & 69 & 118 & 132 & 249 & 867 \\
\hline Prevalence rates of positive cases & $31.21 \%$ & $61.27 \%$ & $95.65 \%$ & $67.80 \%$ & $61.36 \%$ & $37.75 \%$ & - \\
\hline
\end{tabular}

$1=$ below 5 years.

$2=5-10$ years.

$3=11-15$ years.

$4=16-20$ years.

$5=20-25$ years.

$6=26$ years and above

From the table, it can be seen that people between the ages 11 - 15 years have a high prevalence for intestinal parasites. This is in congruence with Ekobo (1997) who stated that, the prevalence of intestinal parasites in children between the ages of 11 and 15 years is higher than any other age group. 
International Journal of Trend in Scientific Research and Development (IJTSRD) @ www.ijtsrd.com eISSN: 2456-6470

ANALYSIS OF HYPOTHESIS 5

Table 7: The prevalence rates of intestinal protozoa according to the different species

\begin{tabular}{|c|c|c|c|}
\hline & \multicolumn{2}{|c|}{ The prevalence rates of intestinal protozoa according to the different species. } \\
\hline Type of intestinal protozoa & $\mathbf{N}^{\circ}$ & Prevalence rate & Position according to prevalence rate \\
\hline E. h & 160 & $53.33 \%$ & 1 \\
\hline E. c & 118 & $39.33 \%$ & 2 \\
\hline T. i & 17 & $5.67 \%$ & 3 \\
\hline G. i & 05 & $1.67 \%$ & - \\
\hline Total & 300 & $100 \%$ & 4 \\
\hline
\end{tabular}

$\mathrm{E} . \mathrm{h}=$ Entamoeba histolytica

E .c $=$ Entamoeba coli

$\mathrm{T} . \mathrm{i}=$ Trichomonas intestinalis

$\mathrm{G} . \mathrm{i}=$ Giardia intestinalis

From the above table, it is shown that, the most prevalent intestinal protozoan was Entamoeba histolytica.

Table 8: The prevalence rates of intestinal helminthes according to the different species

\begin{tabular}{|c|c|c|c|}
\hline & \multicolumn{3}{|c|}{ The prevalence rates of intestinal helminthes according to the different species. } \\
\hline Type of intestinal helminthes & $\mathbf{N}^{\circ}$ present & Prevalence rate & Position according to prevalence rate \\
\hline A. 1 & 90 & $47.37 \%$ & 1 \\
\hline T. $\mathrm{A}$ & 67 & $35.26 \%$ & 2 \\
\hline A. $\mathrm{n}$ & 23 & $12.11 \%$ & 4 \\
\hline Total & 10 & $5.26 \%$ & - \\
\hline
\end{tabular}

A .l = Ascaris lumbricoides

$\mathrm{T} . \mathrm{t}=$ Trichuris trichiura

A. $\mathrm{d}=$ Ankylostoma duodenale

$\mathrm{H} . \mathrm{n}=$ Hymenolepis nana

From the above table, it is shown that, the most prevalent intestinal helminthe is Ascaris lumbricoides.

ANALYSIS OF HYPOTHESIS 6

Table 9: $\mathrm{X}^{2}$ comparison of the prevalence rate of Entamoeba histolytica in both males and females

\begin{tabular}{|c|c|c|c|}
\hline Groups & Females & Males & Total \\
\hline Observed & 92 & 68 & 160 \\
\hline Expected & 80.0 & 80.0 & 160 \\
\hline $\mathrm{X}^{2}$ & 1.80 & 1.80 & 3.60 \\
\hline
\end{tabular}

Total proportion

$\mathrm{X}^{2}=3.60$

$\mathrm{df}=2-1=1\} \boldsymbol{\alpha}>0,05$

The calculated $\mathrm{X}^{2}$ value $=3.60$ the critical or table value of $\mathrm{X}^{2}$ at 0.05 level of significance was 0.455 . Since the calculated value of $\mathrm{X}^{2}$ is greater than the critical value, it shows that the difference is statistically significant and thus the hypothesis that the prevalence rate of Entamoeba histolytica is higher in males than females is retained or validated.

ANALYSIS OF HYPOTHESIS 7

Table 10: The prevalence rates of intestinal protozoa in function of age

\begin{tabular}{|c|c|c|c|c|c|c|c|}
\hline & \multicolumn{3}{|c|}{$\mathrm{N}^{\circ}$ of cases and prevalence rate of intestinal protozoa in function of age. } \\
\hline Type of intestinal protozoa & 1 & 2 & 3 & 4 & 5 & 6 & Total \\
\hline E.h & $\begin{array}{c}21 \\
(80.8 \%)\end{array}$ & $\begin{array}{c}23 \\
(54.8 \%)\end{array}$ & $\begin{array}{c}23 \\
(58.9 \%)\end{array}$ & $\begin{array}{c}21 \\
(38.2 \%)\end{array}$ & $\begin{array}{c}20 \\
(34.05 \%)\end{array}$ & $\begin{array}{c}32 \\
(46.4 \%)\end{array}$ & 153 \\
\hline \multirow{2}{*}{ E.c } & 5 & 15 & 14 & 31 & 33 & 33 & \\
$(19.2 \%)$ & $(35.7 \%)$ & $(35.9 \%)$ & $(56.4 \%)$ & $(56.9 \%)$ & $(47.8 \%)$ & 118 \\
\hline \multirow{2}{*}{ T.i } & - & 4 & 2 & 2 & 5 & 3 & 16 \\
& $(0 \%)$ & $(9.52 \%)$ & $(5.1 \%)$ & $(3.6 \%)$ & $(8.6 \%)$ & $(4.3 \%)$ & 16 \\
\hline \multirow{2}{*}{ G.i } & - & - & - & 1 & - & 1 & 2 \\
$(0 \%)$ & $(0 \%)$ & $(0 \%)$ & $(1.8 \%)$ & $(0 \%)$ & $(1.4 \%)$ & 2 \\
\hline Total & 26 & 42 & 39 & 55 & 58 & 69 & 289 \\
\hline
\end{tabular}

$1=$ below years

$2=5-10$ years

$\mathrm{E} . \mathrm{h}=$ Entamoeba histolytica

$3=11-15$ years

E $. c=$ Entamoeba coli

$4=16-20$ years

$\mathrm{T} . \mathrm{I}=$ Trichomonas intestinalis

$\mathrm{G} . \mathrm{I}=$ Giardia intestinalis

$5=26$ years and above

The figures in brackets are the prevalence rates of intestinal protozoa in function of age.

From the table, it can be seen that the most prevalent intestinal protozoa in children between the ages of 0 - 15 is Entamoeba histolytica 
International Journal of Trend in Scientific Research and Development (IJTSRD) @ www.ijtsrd.com eISSN: 2456-6470

Table 11: The prevalence rates of intestinal helminthes in function of age

\begin{tabular}{|c|c|c|c|c|c|c|c|}
\hline & \multicolumn{6}{|c|}{$\mathrm{N}^{\circ}$ of cases and prevalence rates of intestinal helminthes in function of age. } \\
\hline Type of intestinal protozoa & 1 & 2 & 3 & 4 & 5 & 6 & Total \\
\hline \multirow{2}{*}{ A.l } & $\begin{array}{c}4 \\
(40 \%)\end{array}$ & $\begin{array}{c}21 \\
(70 \%)\end{array}$ & $\begin{array}{c}4 \\
(40 \%)\end{array}$ & $\begin{array}{c}12 \\
(54.5 \%)\end{array}$ & $\begin{array}{c}13 \\
(68.4 \%)\end{array}$ & $\begin{array}{c}12 \\
(52.2 \%)\end{array}$ & 66 \\
\hline \multirow{2}{*}{ T.t } & 6 & 9 & 5 & 5 & 5 & 10 & \\
& $(60 \%)$ & $(30 \%)$ & $(50 \%)$ & $(22.7 \%)$ & $(26.3 \%)$ & $(43.5 \%)$ & 40 \\
\hline \multirow{2}{*}{ A.d } & $(\overline{0 \%})$ & $(\overline{0 \%})$ & $\begin{array}{c}1 \\
(10 \%)\end{array}$ & $\begin{array}{c}5 \\
(22.7 \%)\end{array}$ & $\begin{array}{c}1 \\
(5.3 \%)\end{array}$ & $(\overline{0 \%)})$ & 7 \\
\hline \multirow{2}{*}{ H.n } & $(\overline{0 \%})$ & $(\overline{0 \%})$ & $(\overline{0 \%})$ & $(\overline{0 \%})$ & $(\overline{0 \%})$ & $\begin{array}{c}1 \\
(0 \%)\end{array}$ & 1 \\
\hline Total & 10 & 30 & 10 & 22 & 19 & 23 & 114 \\
\hline
\end{tabular}

$1=$ below 5 years

$2=5-10$ years

A .l = Ascaris lumbricoides

$3=11-15$ years

$\mathrm{T} . \mathrm{t}=$ Trichuris trichiura

$4=16-20$ years

$5=21-26$ years

A $. \mathrm{d}=$ Ankylostoma duodenale

$\mathrm{H} . \mathrm{n}=$ Hymenolepis nana.

$6=26$ years and above.

The figures in brackets are the prevalence rates of intestinal helminthes in function of age

From the table, it can be seen that the prevalent intestinal helminthes in children between the ages of 0 - 15 years are Ascaris lumbricoides and Trichuris trichiura.

\section{ANALYSIS OF HYPOTHESIS 8}

Table 12: Frequencies of associations between intestinal helminthes

\begin{tabular}{|c|c|c|}
\hline Type of association & Helminthes involved & Frequency of occurrence \\
\hline \multirow{2}{*}{ Double associations } & T.t-A.d & 1 \\
\cline { 2 - 3 } & A.l-T.t & 6 \\
\hline Triple associations & A.l-A.d-T.t & 1 \\
\hline
\end{tabular}

A .l = Ascaris lumbricoides

$\mathrm{T} . \mathrm{t}=$ Trichuris trichiura

A $\cdot \mathrm{d}=$ Ankylostoma duodenale

The most frequent associations between intestinal helminthes are those between Ascaris lumbricoides and Trichuris trichiura.

Table 13: Frequencies of associations between intestinal protozoa

\begin{tabular}{|c|c|c|}
\hline \multirow{2}{*}{ Type of Association } & Protozoa involved & Frequency of occurrence \\
\cline { 2 - 3 } & E.h-E.c -647 & 8 \\
\hline Triple Associations & E.c-G.i & 1 \\
\hline
\end{tabular}

$\mathrm{E} \cdot \mathrm{h}=$ Entamoeba histolytica

E .c $=$ Entamoeba coli.

$\mathrm{G} . \mathrm{i}=$ Giardia intestinalis

The most frequent associations between intestinal protozoa are those between Entamoeba histolytica and Entamoeba coli

Table 14: Frequencies of associations between intestinal helminthes and intestinal protozoa

\begin{tabular}{|c|c|c|}
\hline Type of association & Parasites involved & Frequency of occurrence \\
\hline \multirow{4}{*}{ Double association } & T.t-E.h & 1 \\
\cline { 2 - 3 } & T.t-E.c & 4 \\
\cline { 2 - 3 } & A.l-E.h & 3 \\
\cline { 2 - 3 } & A.l-E.c & 3 \\
\cline { 2 - 3 } & A.l-T.i & 1 \\
\cline { 2 - 3 } & A.d-E.h & 1 \\
\cline { 2 - 3 } & A.d-E.c & 1 \\
\hline Triple associations & A .l-A.d-E.h & 1 \\
\hline
\end{tabular}

$\mathrm{T} . \mathrm{t}=$ Trichuris trichiura

A .l = Ascaris lumbricoides

A $. \mathrm{d}=$ Ankylostoma duodenale

$\mathrm{E} \cdot \mathrm{h}=$ Entamoeba histolytica .

E .c $=$ Entamoeba coli

$\mathrm{T} . \mathrm{i}=$ Trichomonas intestinalis

The most frequent associations between intestinal helminthes and intestinal protozoa are those between Trichuris trichiura and Entamoeba coli. 


\section{Discussion of Results}

The epidemiology and pathology of intestinal parasites and consequently the preventive measures and chemotherapeutic methods for treating the diseases caused by these intestinal parasites is of great need in our society especially in the tropical countries which have environments full of parasites because of the favourable climatic conditions. The effects caused by these parasites are dangerous as indicated above.

In this study, a total of 1,387 stool samples were taken from the past records of intestinal parasites from 1995-1996 in the Biyem-Assi hospital laboratory. Table 1 shows that, out of this number, 490 of them were positive for intestinal parasites giving a prevalence rate of $35.33 \%$. This confirms the hypothesis that, the global prevalence of intestinal parasites is below $50 \%$ this result opposes that published by Ekobo (1997) whose prevalence rate lies above 50\%.

Table 2 shows the number of positive and negative cases of intestinal parasites and their prevalence rates. Table 3 shows the steps used in the calculation of $X^{2}$ (chi square) to verify the hypothesis that, the number of positive cases of intestinal parasites is lower than the number of negative cases. The calculated value of $\mathrm{X}^{2}$ was 2.482 but the critical value of $X^{2}$ at 0.05 level of significance was 0.455 . The calculated value of $X^{2}$ was greater than the critical value of $\mathrm{X}^{2}$. Hence the above hypothesis (hypothesis 2) was retained. This statistical test has proven that many referrals for laboratory confirmation of intestinal parasites turn out to be negative. However, this might not be the true picture because some of these patients come for laboratory diagnosis when they had been taking drugs due to the symptoms they had. These drugs, in the process of curing the patient, cause the laboratory results to be negative. Also, the microscopic examination of thin and thick films of faeces is a tedious and strenuous exercise which needs patience. The laboratory technicians might give false negative results after observing the films for sometime without identifying the parasites.

Table 4 shows the number of positive cases of intestinal parasites in males and females and their prevalence rates. Table 5 shows the steps used in the calculation of $\mathrm{X}^{2}$ (chi square) to verify the hypothesis that, males have a higher risk for intestinal parasites than females. The calculated value of $X^{2}$ was 1.174 but the critical value of $X^{2}$ at 0.05 level of significance was 0.455 . The calculated value of $X^{2}$ is greater than the critical value. Hence the above hypothesis (hypothesis 3) was retained. This statistical test has proven that males have a higher risk for intestinal parasites than females. This might be due to the fact that many men than women ate food on the roadside. Men eat roasted beef and pork and other types of food on the roadside. This food is usually not properly cooked (in case of roasted beef and pork) and sometimes, cooked under poor hygienic conditions. This food contains the eggs of helminthes and the cysts of protozoa; this might be why men have a higher risk for intestinal parasites than females.

Table 6 shows the number of positive cases of intestinal parasites in function of age and the percentages of positive cases. From this table, it is clearly seen that people between the ages of 11-15 years have a high prevalence rate of intestinal parasites. This is in conformity with hypothesis 4 . This result is in accordance with Ekobo (1997). This high prevalence of intestinal parasites within the above age group might be due to the fact that, children between the ages of 11-15 years also eat roadside food which carries a high number of helminthe eggs and protozoa cysts.

Table 7 shows four different species of intestinal protozoa, the number of positive cases and their prevalence rates while table 8 shows four different species of intestinal helminthes, the number of positive cases and their prevalence rates. From the two tables, it can be seen that, the most prevalent intestinal protozoa is Entamoeba histolytica and the most prevalent intestinal helminthes is Ascaris lumbricoides. These results are in conformity with hypothesis 5 . These results tally with the fact that, the above two intestinal parasites are most prevalent in the forest zone than the savanna zone. Since Yaoundé being a forest zone, conforms to this result, Ekobo, (1997).

Table 9 shows the steps used in the calculation of $X^{2}$ (chi square) to verify the hypothesis that, the prevalence rate of males for Entamoeba histolytica is higher than that of the females. The calculated value of $\mathrm{X}^{2}$ at 0.05 level of significance was 0.455 . The calculated value of $\mathrm{X}^{2}$ was greater than the critical value of $X^{2}$. Hence the above hypothesis (hypothesis 6) was retained. These results can also be explained from the fact that, many men eat roadside food than females as indicated above.

Table 10 shows how the different species of intestinal protozoa are distributed with respect to age while table 11 shows how the different species of intestinal helminthes are distributed with respect to age. From these tables, it can be seen that the most prevalent intestinal protozoa and intestinal helminthe within the 0-15 age group are Entamoeba histolytica for intestinal protozoa and Ascaris lumbricoides and Trichuris trichiura for intestinal helminthes. These results are in conformity with hypothesis 7. This can be explained from the fact that these parasites are the most prevalent in forest zones and that children of secondary school age eat roadside food.

Table 12 shows the frequency of associations between intestinal helminthes. From this table, the most frequent associations between intestinal helminthes are those between Ascaris lumbricoides and Trichuris trichiura. Table 13 shows the frequency of associations between intestinal protozoa. The most frequent associations between intestinal protozoa are those between Entamoeba histolytica and Entamoeba coli. Table 14 shows the frequency of associations between intestinal helminthes and intestinal protozoa. From this table, the most frequent association between intestinal helminthes and protozoa are those between Trichuris trichiura and Entamoeba coli. These associations are due to the facts that, these parasites can coexist in the alimentary canal of the same individual (host) without affecting each other. This co-existence among intestinal parasites help in that, once particular parasites are isolated, systematic treatment of its associates will be necessary, Ekobo (1997).

\section{SUMMARY OF FINDINGS}

The findings were summarized as follows:

1. The global prevalence of intestinal parasites infestation in the Biyem-Assi neighborhood is 33.35\% 
2. Not all stool samples analysed from patients who present with gastrointestinal symptoms are positive for parasites perhaps because of auto medication

3. Males show a higher prevalence in intestinal parasites than females

4. Children between the ages of 11-15 years are more vulnerable to intestinal parasites.

5. The most common intestinal protozoa is Entamoeba histolytica and the most common helminthe is Ascaris lumbricoides

6. The most prevalent intestinal protozoan between the ages of 0-15 years is Entamoeba histolytica and the most prevalent intestinal helminthes of this age group are Ascaris lumbricoides and Trichuris trichiura

7. Males have a higher risk for Entamoeba histolytica than females

8. The most frequent association between intestinal helminthes is Ascaris lumbricoides and Trichuris trichiura and the association between intestinal protozoa is Entamoeba histolytica and Entamoeba coli. The most frequent associations between intestinal helminthes and intestinal protozoa is Trichuris trichiura and Entamoeba coli.

\section{REFERENCES}

[1] Adetuyibi, A. (1980). Companion to Clinical Medicines in the Tropics. Macmillan Publishers Ltd. London and Basingstoke. Pages 212 - 216

[2] Ashok, R., Suguneswari, G., Satish, K., Kesavaran, V. (2013). Prevalence of Intestinal Parasites Infection in School Going Children in Amalapuram, Andhra Pradesh, India. http://emedicalj.com/en/articles/203

[3] Beaver, P.C., Jung R.C. and Cupp E.W (1884). Clinical Parasitology. Lea and Febiger. Philadelphia. Pages 335 -349 .

[4] Blacklock and Southwell, (1977). A guide to human Parasitology for Medical Practitioners. H. K Lewis and CO Ltd. London. Pages 150 - 170

[5] Brown, H.W. and Neva F.A. (1983). Basic Clinical Parasitology. $5^{\text {th }}$ edition, Prentice hall international INC. Englewood cliffs U.S.A. pages 23 - 37, 99-105 \& 169175

[6] Davidson, I. and Henry J.B. (1969). Clinical Diagnosis by Laboratory Methods. $14^{\text {th }}$ edition. Saunders. Philadelphia. Pages 193-242
[7] Ekobo, S.A. (1997). Santé, Climat et Environnement au Cameroon. Editions Justey-Sciences. Yaoundé. Pages 193-242

[8] Fishbein's Illustrated Medical and Health Encyclopedia, (1978). Stuntman CO-inc. Westport. Vol. 4, pages 783 785.

[9] Gills H.M., Watson-Williams, E.J. and Ball P.A.J. (1964). Hook Worm Infection and Anaemia. Q.J. Med. Pages 2433

[10] Hoge, C.W., Shlim D.R. \& Rajah, R. (1993). Epidemiology of Diarrhea Illness Associated with Coccidian-like Organism among Travelers and Foreign Residents in Nepal. The Lancet VOL $341 \mathrm{~N}^{0} 8854$ pp 1175-1179. Source https:www.ncbi.nlm.gov>pubmed

[11] Jawetz, E., Melnick, J.L. and Adelberg E. (1980). Review of Medical Microbiology. Medical publications. Los altos-california. Pages 556-570.

[12] Lawong, M.M. (1996). "The incidence of Plasmodium falciparium in a Medical Laboratory in Yaoundé". A Retrospective and Prospective study. E.N.S Dissertation. Yaoundé.

[13] Margraith, B.G. (1971). Clinical Tropical Diseases. $5^{\text {th }}$ edition. Blackwell Scientific Publications. Oxford and Edinburgh. Pages 100-108.

[14] Muller, R. (1975). Worms and Diseases. Heinemann London. Pages 10-25 \& 50-60

[15] New Websters Dictionary and Thesaurus of the English language,(1993). Lexicon publications, Inc. Danbury, Page 729.

[16] Ning Tang \& Nian Ji Luo (2003). A Cross-sectional study of Intestinal Parasitic Infections in Rural District of West China. The Canadian Journal of Infectious Diseases. Source htt://www.semanticscholar.org>paper on $22 / 12 / 2018$ at 9.00 am

[17] Oxford Textbook of Medicine, (1987). Oxford University Press. Oxford. Vol. 1, Sections 1-12.

[18] Pascoe, J. et al (1979). Women's Day Consumer Publishing Co. New York. Pages 200-206.

[19] Ram, B.S, Sailesh B. \& Paras K. P. (2013).A Study of Prevalence of Intestinal Parasites. Source https://www.researchgate.net>publication. $22 / 12 / 2018$ at $10.30 \mathrm{am}$

[20] Soulsby, E.J.L, (1965). Textbook of Ventenary Clinical Parasitology: Helminthes. Blackwell, Oxford. Vol, I. sections $15-18$ 